\title{
Recent Studies on the Neuropharmacological Effects of Salvia officinalis L.: A Promising Candidate for Alzheimer's Disease
}

Parisa Hasanein ${ }^{1 *}$, Maryam Sharifi ${ }^{2}$ and Abbasali Emamjomeh ${ }^{3}$

${ }^{1}$ Department of Biology, School of Basic Sciences, University of Zabol, Zabol, Iran

${ }^{2}$ Department of Biology, School of Basic Sciences, Bu-Ali Sina University, Hamedan, Iran

${ }^{3}$ Computational Biotechnology Lab (CBB), Department of Plant Breeding and Biotechnology (PBB), University of Zabol, Zabol, Iran

\begin{abstract}
Salvia is the largest genus of the Lamiaceae family including about 100 species. Salvia officinalis L. (SO) is one of the most appreciated herbs for richness of the essential oil content and its numerous biologically active compounds. SO has been used in herbal medicine for many centuries. In Islamic literature, it is considered as one of the greatest forms of healing medicine. The leaves of the plant have a wide range of biological activities, such as anti-bacterial, fungistatic, virustatic, anticancer, astringent, eupeptic and antihydrotic effects. Recently, this plant has been focused for its application in traditional medicine as well as to find new neurobiological properties. In this review, the up-todate information on the neurobiological effects of SO on the central nervous system will be reviewed. These include analgesic, memory enhancing, neuroprotective, anticonvulsant, anti-addictive, sedative, anxiolytic, and skeletal muscle relaxant effects. Furthermore, chemical compounds responsible for these effects and the clinical studies on this plant are presented and discussed.
\end{abstract}

Keywords: Salvia officinalis L.; Antinociceptive; Memory; Addiction; Neuroprotective

\section{Introduction}

Despite all the considerable improvement in modern medicine, traditional herbal medical profession has always been practiced [1]. Recently, one-third of total drugs (35\%) in the USA and $80 \%$ of drugs used in fast-developing countries such as China and India are derivatives of phyto extracts [2]. However, the rational treatment of CNS disorders by plant extract derived drugs is in its infancy due to the complex chemistry and organization of the CNS and also the complex chemistry and pharmacology of a plant extract [3].

Iran has a rich heritage of medicinal plants of wide diversity, which are used for the treatment of several diseases. One such plant is Salvia officinalis $\mathrm{L}$. (SO) which has several medical effects including antioxidant, antibacterial, fungistatic, antimutagenic, hypolipidaemic, gastroprotective and anti-Helicobacter pylori [4-6]. In Iranian traditional medicine, it is used for treating diarrhea, colic, dyspepsia, asthma, bronchosis, catarrh, cough and depression. Recently, there is a great effort to document the traditional and medical uses of $\mathrm{SO}$ as well as to find new neurobiological effects for this plant (Figure 1). In this review article, we deal with the recent studies on this subject. Furthermore, compositional profile responsible for the neuobiological effects of SO are presented and discussed. Some of the unwanted effects and toxicity of this plant are briefly outlined.

\section{Research Methods}

An extensive search in electronic databases (PubMed, Scopus, Ovid, Wiley, ProQuest, ISI, and Science Direct) were used to identify the pharmacological and clinical studies during 2008-2017, using 'neuropharmacology' and 'Salvia officinalis' as search words.

\section{Taxonomy and Distribution}

SO belongs to the mint family Lamiaceae, subfamily Nepetoideae, tribe Mentheae and genus Salvia. Approximately 240 genera and 7000 species belong to the Lamiaceae family and it is the largest family of the order Lamiales. The genus Salvia is the largest genus of the Lamiaceae family including about 100 species that are either herbaceous or shrubby perennials, rarely biennials or annuals, often strongly aromatic species. Salvia species are commonly grown all around the world, however they are abundantly distributed in Europe around the Mediterranean, in South-East Asia, and Central and South America [7].

\section{Morphology}

SO is an outcrossing, perennial subshrub up to $60 \mathrm{~cm}$ high. Stems are erect or procumbent with numerous fine hairy dark green branches. Leaves are petiolate, elongated, opposite, simple, sometimes with basal

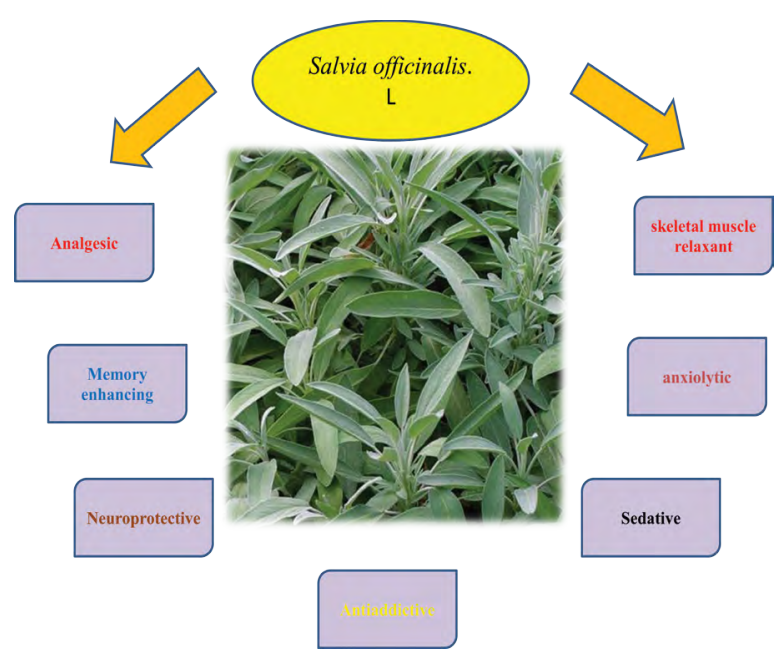

Figure 1: Neurobiological effects of Salvia officinalis $L$.

*Corresponding author: Dr. Parisa Hasanein, Associate Professor, Department of Biology, School of Basic Sciences, University of Zabol, 65178-33391 Zabol, Iran, Tel: +985431232187; E-mail: p.hasanein@uoz.ac.ir

Received November 08, 2017; Accepted November 13, 2017; Published November 18, 2017

Citation: Hasanein P, Sharifi M, Emamjomeh A (2017) Recent Studies on the Neuropharmacological Effects of Salvia officinalis L.: A Promising Candidate for Alzheimer's Disease. Med Chem 7: 348-352. doi: 10.4172/2161-0444.1000479

Copyright: (c) 2017 Hasanein P, et al. This is an open-access article distributed under the terms of the Creative Commons Attribution License, which permits unrestricted use, distribution, and reproduction in any medium, provided the original author and source are credited. 
lobes (especially in juvenile stadium), with serrate margin, rugose surface and more or less contracted at the base. On lower leaf surface hairs are white and on upper surface greenish or greenish-grey. Flowers are on 2-4 mm long pedicel, in pseudoverticillasters with 5-10 flowers that form spurious composed spike. Calyx is 10-14 mm long, hairy, with five teeth. Corolla is ca. $35 \mathrm{~mm}$ long, rosy, violet-blue, rarely white. Flowering period of SO is from March to July depending on habitat climatic conditions [7].

\section{Biochemical Contents and Phytochemistry}

SO is one of the most appreciated herbs for richness of the essential oil content and its numerous biologically active compounds. It is considered to have the highest essential oil yield among Salvia species. The essential oil is extremely complex mixture of different active compounds.

SO has a wide range of constituents include alkaloids, carbohydrate, fatty acids, glycosidic derivatives (e.g., cardiac glycosides, flavonoid glycosides, saponins), poly acetylenes, steroids and waxes $[8,9]$.

The two major chemical classes of secondary metabolites have been identified as typical products of the plant: terpenoids and phenolics compounds (e.g., coumarins, flavonoids, tannins) $[7,10]$. The essential oil of SO mainly comprises the monoterpenes $\alpha$ - and $\beta$-thujone, camphor, 1,8-cineole and borneol, and sometimes in larger amounts sesquiterpenes $\alpha$-humulene and $\beta$-caryophyllene. The diterpenes (e.g., carnosic acid), triterpenes (e.g., oleanoic and ursolic acids), have been found in the leaves. Among the phenolics, SO contains rosmarinic, caffeic, salvianolic compounds, etc [7]. Alcoholic and aqueous extracts of SO are rich in flavonoids. Rosmarinic acid and ellagic acid are the most abundant flavonoids in SO infusion extract, followed by rutin, chlorogenic acid, and quercetin [11]. Table 1 shows the main flavonoids and terpenes found in SO.

The essential oil yield of SO and its chemical composition has attracted the focus of many investigations worldwide. It depends on various factors, such as genetic background, locality, environmental conditions, season, physiological stage, plant parts used for the extraction of essential oil and soil mineral fertilization [7]. For instance, the highest content of rosmarinic acid in SO leaves was detected when collections occurred in May, July and September [7].

Another important point is the extreme variability in preparation methods that may greatly influence the relative amounts of active compounds present in SO extracts. For example, Martins et al. [12] reported that decoction gave the most pronounced antioxidant and the highest concentration of phenolic compounds compared to methanol/ water extract and infusion. Other factor like ratios of amount-tosolvent, solvent temperature and duration of immersion may also change extract potency.

\begin{tabular}{|c|c|}
\hline Flavonoids & Terpenes and terpenoids \\
\hline Apigenin & Borneol \\
\hline Cirsimaritin & Camphor \\
\hline Ellagic acid & Carnosol \\
\hline Genkwanin & Ursolic acid \\
\hline Hispidulin & Cineole \\
\hline Luteolin & Oleanolic acid \\
\hline Quercetin & Limonene \\
\hline Rosmarinic acid & Linalool \\
\hline Rutin & a-Thujone \\
\hline
\end{tabular}

Table 1: Common flavonoids and terpenes isolated from Salvia officinalis $L$.

\section{Neurobiological Effects}

\section{Analgesic and anti-inflammatory effects}

The analgesic and anti-inflammatory effects of SO have been demonstrated in different experimental models. For example, in experimental model of hot plate test, SO leaf aqueous $(10,31.6,100$, $316,1000 \mathrm{mg} / \mathrm{kg})$ and butanol $(10,31.6,100,316 \mathrm{mg} / \mathrm{kg})$ extracts increased, in a dose-dependent manner, the latency time taken by the animals to start licking their hind paw when subjected to the hot-plate. Also, in this study, SO leaf aqueous and butanol extracts decreased the licking time in both early and late phases of formalin test. Decrease in licking time in both phases was dose-dependently [13]. These effects were accompanied by inhibition of inflammation using the cotton pellet granuloma and carrageenan-induced paw edema in rats. The anti-inflammatory action of SO may be related to manool, carnosol, and ursolic acid which are main terpenes/terpenoids of the plant $[14,15]$. It has been reported that anti-inflammatory effect of ursolic acid is twofold more potent than that of indomethacin [16]. This action of SO constituents may be responsible for its antinociceptive effect in patient with pharyngitis [17].

The results of an investigation done by Abad et al. [18] indicated that injection of SO $(100 \mathrm{mg} / \mathrm{kg}$, i.p.) at $30 \mathrm{~min}$ before hind paw injection of formalin decreased pain responses (time of licking and biting of injected paw) of the second phase. In another part of this study, SO administration showed analgesic effects in an experimental model of neuropathic pain induced by vincristine. In this regard, intravenous administration of vincristine caused significant increase in the second phase of formalin test and SO could alleviate pain responses induced by vincristine. In another case that studied by Rodrigues et al., it has been shown that oral administration of hydroalcholic extract of SO $(3,10$, 30 and $100 \mathrm{mg} / \mathrm{kg}$ ) inhibits the neurogenic phase of formalin-induced nociceptive response with inhibition of $28 \pm 2,36 \pm 7,42 \pm 2$ and 36 $\pm 3 \%$, respectively. However, only the doses of 10,30 and $100 \mathrm{mg} / \mathrm{kg}$ of the extract reduced the inflammatory phase by $36 \pm 5,51 \pm 8$ and $33 \pm 10 \%$, respectively. According to this experiment, it was indicated that hydroalcholic extract of SO (10 and $30 \mathrm{mg} / \mathrm{kg}$, i.g.) significantly reduced the nociception induced by glutamate, capsaicin and in rats. In another part of this study, the isolated compounds from the extract, carnosol $(10 \mathrm{mg} / \mathrm{kg})$ and mixture of ursolic acid/oleanolic acid $(30 \mathrm{mg} /$ $\mathrm{kg}$ ), did not alter the neurogenic phase but reduced the inflammatory phase of formalin. Furthermore, these compounds reduced the nociceptive behavior induced by cinnamaldehyde but did not alter the cinnamaldehyde-induced paw oedema measured during $4 \mathrm{~h}$ [19].

In the tail-flick test, treatment of rats with hydroalcoholic extract of $\mathrm{SO}(600$ and $800 \mathrm{mg} / \mathrm{kg}$, i.g.) increased percentage of maximum possible effect (\%MPE) compared to vehicle group [20]. Furthermore, concomitant treatment with SO $800 \mathrm{mg} / \mathrm{kg}$ and morphine prevented the development of tolerance to the analgesic effect of morphine on day 7 of morphine administration. These results showed that SO may decrease tolerance induced by repeated morphine administration [20].

\section{Memory enhancing effect}

Memory effects of SO have shown in many previous studies [10,2128]. In an active avoidance paradigm apparatus, SO- treated mice showed significant reduction in number of avoidance and discrimination errors during retention trial compared to control group. In this study, aacetylcholin esterase (AChE) activity was also significantly decreased $38 \%$ in mice treated with the extract [28]. Furthermore, others studies have shown that ethanolic extracts of SO significantly inhibit AChE in a dose dependent manner. Vladimir-Knežević et al. [29] reported that SO has AChE inhibition activity above $75 \%$ at $1 \mathrm{mg} / \mathrm{mL}$. In another 
work, it has been found that essential oil of SO inhibits $46 \%$ of AChE activity at a concentration of $0.5 \mathrm{mg} / \mathrm{ml}[30]$.

In a passive avoidance learning task, injection of ethanolic extract of $\mathrm{SO}(50,100 \mathrm{mg} / \mathrm{kg}$, i.p.) immediately after the training session, increased step-through latencies showing enhancement of memory retention. In this investigation, ethanolic extract interacted with pilocarpine, scopolamine, nicotine and mecamylamine and in all tests, ethanolic extract increased memory retention [22].

The effect of SO on the acquisition and retention memory of nondiabetic and diabetic rats was studied by Hasanein et al. In this study it has been found that $\mathrm{SO}(400 \mathrm{mg} / \mathrm{kg}$, i.g.) did not influence the number of trials to acquisition, the step-through latency (STLr) and the time spent in the dark compartment (TDC) of control group and diabetic animals, however SO at 600 and $800 \mathrm{mg} / \mathrm{kg}$ induced a decrease in the number of trials to acquisition in non-diabetic rats. Also, in the retention test, SO at 600 and $800 \mathrm{mg} / \mathrm{kg}$ caused increased STLr in control group compared to untreated control group. Furthermore, it has been reported that rosmarinic acid as a main phenol compounds found in SO has memory enhancing properties in some experimental models of memory. For example, rosmarinic acid ( $32 \mathrm{mg} / \mathrm{kg}$, i.g.) had comparable effects with donepezil in prevention of acquisition and retention memory impairment induced by ethanol [31]. In another study, orally rosmarinic acid administration (16 and $32 \mathrm{mg} / \mathrm{kg}$ ) improved learning and memory of control rats and reversed learning and memory deficits of scopolamine received groups [32].

On the basis of traditional medicine, the in vitro cholinergic binding properties and the modulation of mood and cognitive performance in humans, it was thought that $\mathrm{SO}$ might potentially provide a novel natural treatment for Alzheimer's disease.

In a randomised, single-blinded design (participant-masked), Moss et al. also reported that SO aroma produce a significant enhancement effect for the quality of memory factor in healthy volunteers. This enhancement was restricted to aspects of long term or secondary memory with no impact on working memory performance. This examination also showed that $\mathrm{SO}$ aroma increase alertness from preto post-testing compared to a decrease in the control condition [25].

The results of another clinical trial indicated that a certain dose (333 mg) of standardized extract of SO in older adults was associated with significant enhancement of secondary memory performance at all testing times. There were also significant improvements to accuracy of attention following the $333 \mathrm{mg}$ dose [27].

Kennedy et al. found that administration of $150 \mathrm{mg}$ of SO dried leaf extract improves mood and cognitive performance in healthy young participants.

In one placebo-controlled clinical trial, the efficacy and safety of SO extract in patients with mild to moderate Alzheimer's disease was evaluated using a fixed dose and over a 4-month period in three centers in Tehran. The results indicated that after 4 months, the S. officinalis extract 60 drops / day produced a significantly better outcome on cognitive function than placebo in Clinical Dementia Rating Scale (CDR) [21].

Therefore, these researches support the cognitive-enhancing effects of SO. Although SO shows positive effects in the small sample sizes and short treatment duration, its effects in larger populations with Alzheimer's disease require investigation.

\section{Neuroprotective effect}

SO has shown antioxidant activity in several neurobehavioral studies. For example, it has been reported that aqueous extracts of $\mathrm{SO}$ leaf have a high ability to protect the brain and liver homogenates from both Fe (II)-and SNP-induced lipid peroxidation in vitro; this high protective ability of the extract may be due to the antioxidant effect of the high vitamin $\mathrm{C}$ and total phenol content of the leaf. However, the main mechanism through which they bring about their protection is by their $\mathrm{Fe}(\mathrm{II})$ chelating ability, reducing power, and NO radical scavenging ability, but their $\mathrm{OH}$ radical scavenging ability is low [26]. In another examination, it has been reported that some chemicals of SO including carnosic acid, carnosol, rosmanol and caffeic acid are responsible for the free radical scavenging activity of SO [33]. The most effective antioxidant constituents of $\mathrm{SO}$ are carnosol, rosmarinic acid, and carnosic acid, followed by caffeic acid, rosmanol, rosmadial, genkwanin, and cirsimaritin [34]. The radical scavenging effect of carnosol is comparable to that of $\alpha$-tocopherol [35].

\section{Anti- seizure effects}

Anti-seizure effects of SO has been reported in an investigation by Khayate-Nouri et al. [36]. In this study, intra peritoneal injection of SO $(1 \mathrm{~g} / \mathrm{kg}), 30$ minutes before seizure test caused increase in threshold. This increase was statistically significant compared with control group. However, the findings of a case study had opposite results. In this study, it was reported that in two cases, those of a newborn and a toddler, experienced generalized tonic-clonic seizures was appeared after accidental exposure to SO oil [37]. The presence of thujones, camphor and 1,8-cineol in its essential oils may be responsible for this adverse effect. There are also several case reports exiting in the literature, where SO oil caused clonic spasms and tonic-clonic convulsions, with muscle dystonia [38,39].

\section{Anti-addiction effect}

The anti-addictive of different doses of SO has been reported by Hasanein et al. The results of this experimental study revealed that the higher doses of SO extract (600 and $800 \mathrm{mg} / \mathrm{kg}$, i.g.) significantly attenuated weight loss and number of teeth chattering events in the morphine-dependent rats compared to untreated morphine-dependent group. Also, SO at different doses has effect on the number of penis licking events in morphine-dependent rats such that, at the doses of 400 , 600 and $800 \mathrm{mg} / \mathrm{kg}$ significantly reduced the number of penis licking events in the morphine-dependent groups. In this examination, higher doses of SO extract $(600$ and $800 \mathrm{mg} / \mathrm{kg}$ ) attenuated the withdrawal signs including wet dog shakes and sniffing. SO $800 \mathrm{mg} / \mathrm{kg}$, but not 600 $\mathrm{mg} / \mathrm{kg}$, also reduced rearing, standing, face grooming and paw tremor in SO $800 \mathrm{mg} / \mathrm{kg}$ treated-morphine dependent rats [10].

\section{Sedative and hypnotic effects}

This plant is a traditional medicinal plant used as a sedative in Latin America. Carnosol and carnosic acid which isolated from the dried leaves inhibit $\left[{ }^{35} \mathrm{~S}\right]$ tertiary butylbicyclophosphorothionate $\left(\left[{ }^{35} \mathrm{~S}\right] \mathrm{TBPS}\right)$ binding to rat brain membranes in vitro. This ligand is considered to bind to the chloride channel of the GABA/benzodiazepine receptor complex in brain tissue [40]. In another study, a benzodiazepine receptor binding assay-guided, fractionation of the methanol extract from SO leaves revealed three flavones and two abietane diterpenes function as benzodiazepine receptor-active components. Also, some substances like flavones, apigenin, hispidulin and cirsimaritin competitively inhibited ${ }^{3} \mathrm{H}$-flumazenil binding to the benzodiazepine receptor with $\mathrm{IC}_{50}$ values of 30, 1.3 and $350 \mathrm{mM}$, respectively [33].

Rosmarinic acid and caffeic acid are phenolic compound of SO which show antidepressant and anxiolytic-like activity. Interestingly, it has been reported that these substances could no change the uptake of 
monoamines to synaptosomes or mitochondrial monoamine oxidase activity in the mouse brain. Therefore, it seems that they induce their antidepressant effects by mechanisms other than the inhibition of monoamine transporters and monoamine oxidase [41].

The hypnotic effects of SO has been reported recently in an experimental model of pentobarbital sodium-induced sleeping time test [10]. The findings indicate that SO extract has positive effect on sleeping time and sleep latency induced by pentobarbital. In this study, it was proved that SO at doses of 400 and $600 \mathrm{mg} / \mathrm{kg}$ did not affect sleep latency compared to the vehicle-treated group. However, SO 800 $\mathrm{mg} / \mathrm{kg}$ caused a significant decrease in sleep latency of treated rats, which was not statistically different from the reference drug diazepam. Furthermore, SO (600 and $800 \mathrm{mg} / \mathrm{kg}$ ) significantly increased sleep duration of treated rats compared to the vehicle-treated group [10].

\section{Muscle relaxant}

The effect of SO against spontaneous contraction in rabbit was studied by Aslam Khan et al. [42]. In this study, it was found that a crude extract of SO protects from diarrhea with gut relaxation. These results provide the pharmacological base for medicinal use of SO in treatment of gut disorders, such as diarrhea and abdominal colic. In another study, the hydroalcoholic extract of SO $(10,30$ and $100 \mathrm{mg} /$ $\mathrm{kg}$ ) decreased the number of abdominal constrictions that induced by acetic acid in female Swiss mice [15]. The results of a current study showed that Salvigenin, one of the active flavonoids existing in SO, can reduce the number of abdominal contractions at doses of 50 and $100 \mathrm{mg} / \mathrm{kg}$. Increasing dose of Salvigenin, with reduction in abdominal cramps resulted in the increasing of pain inhibition, and the percentage of this inhibition was statistically significant [19].

\section{Adverse Effects}

There is no reported adverse effect after acute administration of SO which confirms its safety in single intake. Some unwanted gastrointestinal side effects have been reported after prolonged use or following overdose of ethanolic extract and volatile oil of SO [34]. However, precautions should be taken regarding its (uncontrolled) usage due to the varying levels of thujones [39]. Thujone is considered as the most toxic compounds in SO oil. Thujone causes excitation and convulsions in a dose-dependent manner by inhibiting $\mathrm{GABA}_{\mathrm{A}}$ receptors in the central nervous system. Although this effect is mostly confirmed in animal studies, severe intoxication has been reported in humans after consumption of essential oils rich in thujone [43].

\section{Future Concerns}

Presently, the majority of human studies assessed cognitiveenhancing effects of SO, so its efficacy in other brain disorders in clinical trials is uncertain. Another point is the extreme variability in methods of plant preparation which may greatly influence the relative amounts of active compounds present in SO. Ethanolic, methanolic, aqueous extracts along with the essential oils of SO have been used. This is an issue that needs consideration in future studies as the extracts used are likely to influence outcomes. Taken together, evidence for the cognitive-enhancing and neuroprotective effects of $\mathrm{SO}$ are promising. However, greater effort is needed to elucidate the potential of this plant in treating other neuropathological conditions in human.

\section{Conflict of Interest}

None declared.

\section{References}

1. Mollazadeh $\mathrm{H}$, Hosseinzadeh $\mathrm{H}$ (2014) The protective effect of Nigella sativa against liver injury: a review. Iran J Basic Med Sci 17: 958-966.
2. Kumar AM, Bansal P, Kumar S (2009) Plants-herbal wealth as a potential source of ayurvedic drugs. Asian J Trad Med 4: 152-170.

3. Houghton PJ, Seth P (2003) Plants and the central nervous system. Pharmacol Biochem Behav 75: 501-512.

4. Mayer B, Baggio CH, Freitas CS, dos Santos AC, Twardowschy A, et al. (2009) Gastroprotective constituents of Salvia officinalis L. Fitoterapia 80: 421-426.

5. Khakpour SH, Najari M, Belasei FT, Khosravi M, Belasei MF, et al. (2014) Hepatoprotective and antioxidant effects of Salvia officinalis L. hydroalcoholic extract in male rats. Chin Med 5: 130-136.

6. Rodrigues MR, Kanazawa LK, das Neves TL, da Silva CF, Horst $\mathrm{H}$, et al. (2012) Antinociceptive and anti-inflammatory potential of extract and isolated compounds from the leaves of Salvia officinalis in mice. J Ethnopharmacol 139: 519-526.

7. Grdiša $M$, Jug-dujaković $M$, Lončarić $M$, Carović-stanko $K$, Ninčević $T$, et al. (2015) Dalmatian sage (Salvia officinalis L.): A review of biochemical contents, medical properties and genetic diversity. Agricul Cons Sci 2: 69-78.

8. Russo A, Formisano C, Rigano D (2013) Chemical composition and anticancer activity of essential oils of Mediterranean sage (Salvia officinalis L.) grown in different environmental conditions. Food Chem Toxicol 55: 42-47.

9. Veličković DT, Ranđelović NV, Ristić MS, Veličković AS, Šmelcerović AA (2003) Chemical constituents and antimicrobial activity of the ethanol extracts obtained from the flower, leaf and stem of Salvia officinalis L. J Serb Chem Soc 68: 17-24.

10. Miroddi M, Navarra M, Quattropani M, Calapai F, Gangemi S, et al. (2014) Systematic review of clinical trials assessing pharmacological properties of Salvia species on memory, cognitive impairment and Alzheimer's disease. CNS. Neurosci Ther 20: 485-485.

11. Hernandez-Saavedra D, Perez-Ramirez IF, Ramos-Gomez M, Mendoza-Diaz S, Loarca-Pina G, et al. (2016) Phytochemical characterization and effect of Calendula officinalis, Hypericum perforatum, and Salvia officinalis infusions on obesity associated cardiovascular risk. Med Chem Res 25: 163-172.

12. Martins N, Barros L, Santos-Buelga C, Henriques M, Silva S, et al. (2015) Evaluation of bioactive properties and phenolic compounds in different extracts prepared from Salvia officinalis L. Food Chem 170: 378-385.

13. Qnais EY, Abu-Dieyeh M, Abdulla FA, Abdalla SS (2010) The antinociceptive and anti-inflammatory effects of Salvia officinalis leaf aqueous and butanol extracts. Pharm Biol 48: 1149-1156.

14. Nicolella H, Senedese J, Furtado R, Veneziani R, Tavares D (2015) Evaluation of anti-inflammatory potential of diterpene manool in macrophages by quantification of nitric oxide. J Int Soc Sports Nutr 1: 124-128.

15. Rodrigues MR, Kanazawa LK, das Neves TL (2012) Antinociceptive and antiinflammatory potential of extract and isolated compounds from the leaves of Salvia officinalis in mice. J Ethnopharmacol 139: 519-526.

16. Baricevic D, Sosa S, Della Loggia R (2001) Topical anti-inflammatory activity of Salvia officinalis L. leaves: the relevance of ursolic acid. J Ethnopharmacol 75: 125-132.

17. Hubbert M, Sievers H, Lehnfeld R, Kehrl W (2006) Efficacy and tolerability of a spray with Salvia officinalis in the treatment of acute pharyngitis - a randomised, double-blind, placebo-controlled study with adaptive design and interim analysis. Eur J Med Res 11: 20-26.

18. Abad ANA, Khayate Nouri M, Tavakkoli F (2011) Effect of Salvia officinalis hydroalcoholic extract on vincristine-induced neuropathy in mice. Chin $\mathrm{J}$ Nat Med 9: 354-358.

19. Mansourabadi A, Mohammad Sadeghi H, Razavi N, Rezvani E (2015) Antiinflammatory and analgesic properties of Salvigenin, Salvia officinalis flavonoid extracted. Advanced Herbal Med 1: 31-41.

20. Hasanein P, Teimuri Far M, Emamjomeh A (2015) Salvia officinalis L. attenuates morphine analgesic tolerance and dependence in rats: possible analgesic and sedative mechanisms. Am J Drug Alcohol Abuse 41: 405-413.

21. Akhondzadeh S, Noroozian M, Mohammadi M, Ohadinia S, Jamshidi AH, et al. (2003) Salvia officinalis extract in the treatment of patients with mild to moderate Alzheimer's disease: a double blind, randomized and placebo-controlled trial. $J$ Clin Pharm Ther 28: 53-59.

22. Eidi M, Eidi A, Bahar M (2006) Effects of Salvia officinalis L. (sage) leaves on memory retention and its interaction with the cholinergic system in rats. Nutr 22: 321-326. 
Citation: Hasanein P, Sharifi M, Emamjomeh A (2017) Recent Studies on the Neuropharmacological Effects of Salvia officinalis L.: A Promising Candidate for Alzheimer's Disease. Med Chem 7: 348-352. doi: 10.4172/2161-0444.1000479

23. Iuvone T, De Filippis D, Esposito G, D’Amico A, Izzo AA (2006) The spice Sage and its active ingredient rosmarinic acid protect PC12 cells from amyloid- $\beta$ peptide-induced neurotoxicity. J Pharmacol Exp Ther 317: 1143-1149.

24. Kennedy DO, Pace S, Haskell C, Okello EJ, Milne A, et al. (2006) Effects of cholinesterase inhibiting Sage (Salvia officinalis) on mood, anxiety and performance on a psychological stressor battery. Neuropsychopharmacol 31: 845-852.

25. Moss L, Rouse M, Wesnes KA, Moss M (2010) Differential effects of the aromas of Salvia species on memory and mood. Hum Psychopharmacol Clin Exp 25: 388-396

26. Oboh G, Henle T (2009) Antioxidant and inhibitory effects of aqueous extracts of Salvia officinalis leaves on pro-oxidant-induced lipid peroxidation in brain and liver in vitro. J Med Food 12: 77-84

27. Scholey AB, Tildesley NT, Ballard CG, Wesnes KA, Tasker A, et al. (2008) An extract of Salvia (sage) with anticholinesterase properties improves memory and attention in healthy older volunteers. Psychopharmacol 198: 127-139.

28. Smach MA, Hafsa J, Charfeddine B, Dridi H, Limem K (2015) Effects of sage extract on memory performance in mice and acetylcholinesterase activity. Annales Pharmaceutiques Françaises 73: 281-288.

29. Vladimir-Knežević S, Blažeković B, Kindl M, Vladić J, Lower-Nedza, AD, et al. (2014) Acetylcholinesterase inhibitory, antioxidant and phytochemical properties of selected medicinal plants of the Lamiaceae family. Molecules 19: 767-782.

30. Ferreira A, Proença C, Serralheiro MLM, Araújo MEM (2006) The in vitro screening for acetylcholinesterase inhibition and antioxidant activity of medicinal plants from Portugal. J Ethnopharmacol 108: 31-37.

31. Hasanein P, Seifi R, Hajinezhad MR, Emamjomeh A (2016) Rosmarinic acid protects against chronic ethanol-induced learning and memory deficits in rats. Nutr Neurosci 1: 1-8.

32. Hasanein P, Mahtaj AK (2015) Ameliorative effect of rosmarinic acid on scopolamine-induced memory impairment in rats. Neurosci Lett 85: 23-27.

33. Imanshahidi M, Hosseinzadeh H (2006) The pharmacological effects of Salvia species on the central nervous system. Phytother Res 20: 427-437.

34. Ghorbani A, Esmaeilizadeh M (2017) Pharmacological properties of Salvia officinalis and its components. J Tradit Complement Med 7: 433-440.

35. Dianat M, Esmaeiliziadeh M, Badavi M, Samarbafzadeh A, Naghizadeh $B$ (2014) Cardiac protective effects of crocin on hemodynamic parameters and infarct size in compare vitamin $\mathrm{E}$ after ischemia reperfusion in isolated rat heart. Planta Med 80: 393-398.

36. Khan A, Rehman N, AlKharfy MK, Gilani AH (2011) Antidiarrheal and antispasmodic activities of Salvia officinalis are mediated through activation of $\mathrm{K}^{+}$channels. Bangladesh. J Pharmacol 6: 111-116.

37. Halicioglu O, Astarcioglu G, Yaprak I, Aydinlioglu H (2011) Toxicity of Salvia officinalis in a newborn and a child: an alarming report. Pediatric Neurol 45: 259-260.

38. Burkhard PR, Burkhardt K, Haenggeli CA, Landis T (1999) Plant induced seizures: Reappearance of an old problem. J Neurol 246: 667-670.

39. Radulović NS, Genčić MS, Stojanović NM, Randjelović PJ, Stojanović-Radić ZZ, et al. (2017) Toxic essential oils. Part V: Behaviour modulating and toxic properties of thujones and thujone-containing essential oils of Salvia officinalis L., Artemisia absinthium L., Thuja occidentalis L. and Tanacetum vulgare L. Food Chem Toxicol 105: 355-369.

40. Rutherford DM, Nielsen MP, Hansen SK, Witt MR, Bergendorff O, et al. (1992) Isolation and identification from Salvia officinalis of two diterpenes which inhibit t-butylbicyclophosphoro $\left[{ }^{35} \mathrm{~S}\right]$ thionate binding to chloride channel of rat cerebrocortical membranes in vitro. Neurosei Lett 135: 224-226.

41. Lopresti AL (2017) Salvia (Sage): A Review of its Potential Cognitive-Enhancing and Protective Effects. Drugs in R\&D 17: 53-64.

42. Khan A, Rehman N, AlKharfy KM, Gilani AH (2011) Antidiarrheal and antispasmodic activities of Salvia officinalis are mediated through activation of $\mathrm{K}^{+}$channels. Bangladesh. J Pharmacol 6: 111-116.

43. Pelkonen O, Abass, K, Wiesner J (2013) Thujone and thujone-containing herbal medicinal and botanical products: toxicological assessment. Regul Toxicol Pharmacol 65: 100-107. 